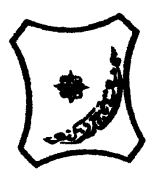

Bayero Journal of Pure and Applied Sciences, 8(1): 29 - 32

Received: February, 2015

Accepted: June, 2015

ISSN $2006-6996$

\title{
ASSESSMENT OF SPEED OF WRITING AMONG LEFT-HANDED AND RIGHT- HANDED UNDERGRADUATE STUDENTS OF UNIVERSITY OF BENIN
}

\author{
*Agoreyo, F.O. and Omigie, M.I.
}

Department of Physiology, School of Basic Medical Sciences, University of Benin, Benin City.

Department of Physiology School of Basic Medical Sciences, University of Benin, Benin City.

*Correspondence author: agoreyofo@yahoo.com

\begin{abstract}
The term handedness describes a characteristic form of specialization whereby a person by preference uses one hand for clearly identified activities, such as writing. In most manual tasks usually, the preferred hand is used more than the unpreferred hand The aim of this study was to compare the speed in writing of left-handed and right-handed undergraduates at University of Benin. One hundred (100) undergraduate students irrespective of gender were used. Fifty of the students were males while the remaining fifty were females. Fifty (50) were left-handed and fifty (50) were right -handed. The students were made to undergo a speed test in writing and the time taken to complete the test was recorded in seconds. Result was expressed as Mean ISEM. Difference between means were assessed using students $t$-test and $p$ value less than 0.05 $(p<0.05)$ was chosen for significance. Results showed no significant difference in the speed of writing between left-handed users and right-handed users, though the right-handers were slightly faster. When the right-handers and left-handers used their non dominant hand, left-handers were faster. In the change from dominant hand to non-dominant hand, left-handers were faster. This can be applied in post traumatic rehabilitation involving damage to the dominant hand.

Keywords: Dominant hand, Left-handed, Right-handed, Speed, Writing.
\end{abstract}

\section{INTRODUCTION}

Hand preference is the natural inclination of a person to perform a certain task with one hand rather than another, and proficiency is the dexterity a person exhibits while performing a task (Beukelaar and Kroonenberg, 1983). Handedness is recognised as a particularly human lateralisation characteristic, even though the exact aetiology is unknown (Gail and Gillian 2006). but there is a widespread believe that the condition is hereditary. Hand preference is recognised as an integral part of brain function, rather than a pure function of the hands themselves (Reynolds et al., 1981). Handedness is one of the most important examples of cerebral dominance in human (Siebner et al., 2002). The area of the brain responsible for writing ability is the most posterior part of the middle frontal gyrus and its adjacent area which coordinate fine movement of the muscles of the hand. .Handedness is perhaps the most blatant behavioural asymmetry observed in humans (Corey et. al, 2001). .The term handedness however may refer either to hand preference or to the asymmetrical performance of manual tasks (Triggs et al., 2000). Interest in hand preference is because of its impact on skill and relation to brain function (Corballis, 2003). In most manual task usually, the preferred hand is used more than the unprefered hand (Hausmann et al., 2004). However variation in task performance depends on muscular activity that has 3 components: force, speed and accuracy and these components are further to a limited extent influenced by factors like age, sex, physical environment and energy to perform the task (Kumar and Mandal, 2004).

In a scientific study, it should be recognized that handedness is not a discrete variable (right or left), but a continuous one that can be expressed at various levels between strong left and strong right.

In contrast to other primate the majority of humans prefer the right hand for skilled manipulation. Independent of cultural background, $90 \%$ of humans are right handed (Corballis, 2003), while the remaining $10 \%$ consisting of persons variably identified as left-handed, ambidextrous, and/or ambiguously handed, with somewhat higher rates among males than females (Vuoksimaa et al., 2009). For much of history, left-handedness was viewed with deep suspicion. During the Middle Ages, left-handed writers were thought to be possessed by the Devil, generating the modern sense of the word "sinister" from (sinistra), the Latin word for "left." The English word "left" itself comes from the Old English "lyft", meaning idle, weak or useless. Historically, left-handers have often been compelled by their parents and schools to use their right hand for writing and other tasks. In parts of India, for example, a child showing preference for his left hand will have that hand tied behind his back and, should that fail to switch his preference, his left arm will be broken (Perelle and Ehrman, 2005). 
Lesser forms of such compulsion are evident across a variety of settings, though such compelled switching is increasingly rare in the United States and other high income nations. If anything, left handedness has come into vogue in recent decades, with modern proponents who argue that left-handedness is overrepresented among highly talented individuals. This study was thus meant to study and compare the writing speeds of right and left handed individuals and speed of change from dominant to non dominant hand.

\section{MATERIALS AND METHOD \\ Subjects}

The subjects of this study were 100 undergraduate students (fifty males and fifty females) of the University of Benin, Benin-city, Edo state. Subjects were selected by random sampling after excluding ambidextrous subjects (able to use both hands equally well). Of the subjects tested, 50 were lefthanded, 50 were right-handed.

\section{Experimental Design}

Each subject was given a briefing on the part they were to play as subjects in the research project. All were supplied with foolscap paper, and pens. For the speed test each subject was given a foolscap paper to write as fast with his or her dominant hand, and the time was recorded at the end of the writing. After completion of this first test, the subject rested for about five minutes for muscle relaxation, after which the same text was written with the non-dominant hand not used in writing. This procedure was done for both the 50 left-handed and the 50 right-handed volunteers. The normal left handers served as control to the left handed experimental groups while the normal right handers served as control to the right handed experimental groups.

The time in seconds taken to complete the writing of the text was recorded. The records of the time used by the 50 left-handers were taken in seconds and recorded on a table. The same was done for the 50 right-handers. The time was also taken in seconds in the change when left-handers used right hands and when right handed users used left hand.

\section{Statistical Analysis}

Microgram statistical software (Graph pad.uk version 5) was used in all the statistical analyses. The results were expressed as mean \pm SEM. The significant difference of test and control was detected using student t-test and $\mathrm{p}$-value less than 0.05 were considered significant.

\section{RESULT}

Table 1: Descriptive Statistics of the Time taken for Completing a Specific Writing task in Left and Right handed users.

\begin{tabular}{llc}
\hline HAND USED & LEFT HANDED USERS & RIGHT HANDED USERS \\
\hline DOMINANT (sec) & $297.68 \pm 7.19$ & $292.04 \pm 7.93$ \\
NON-DOMINANT (sec) & $820.50 \pm 16.69$ & $1019.34 \pm 30.12^{* *}$ \\
DIFFERENCE (sec) & $522.82 \pm 13.59$ & $727.30 \pm 27.27^{* *}$ \\
\hline
\end{tabular}

$* * \mathrm{P}<0.05$ Considered significant different.

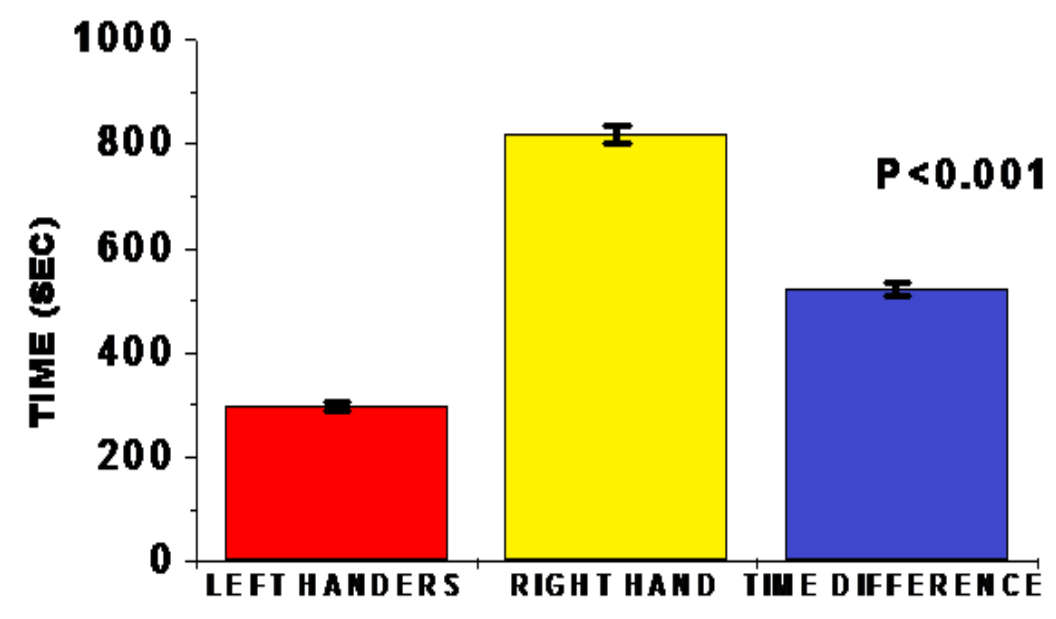

CHANGE IN SPEED OF WRITING

Figure 1: Difference in the speed of writing from left to right hand in seconds $(n=50)$; Means \pm SEM. $P<0.001$ 


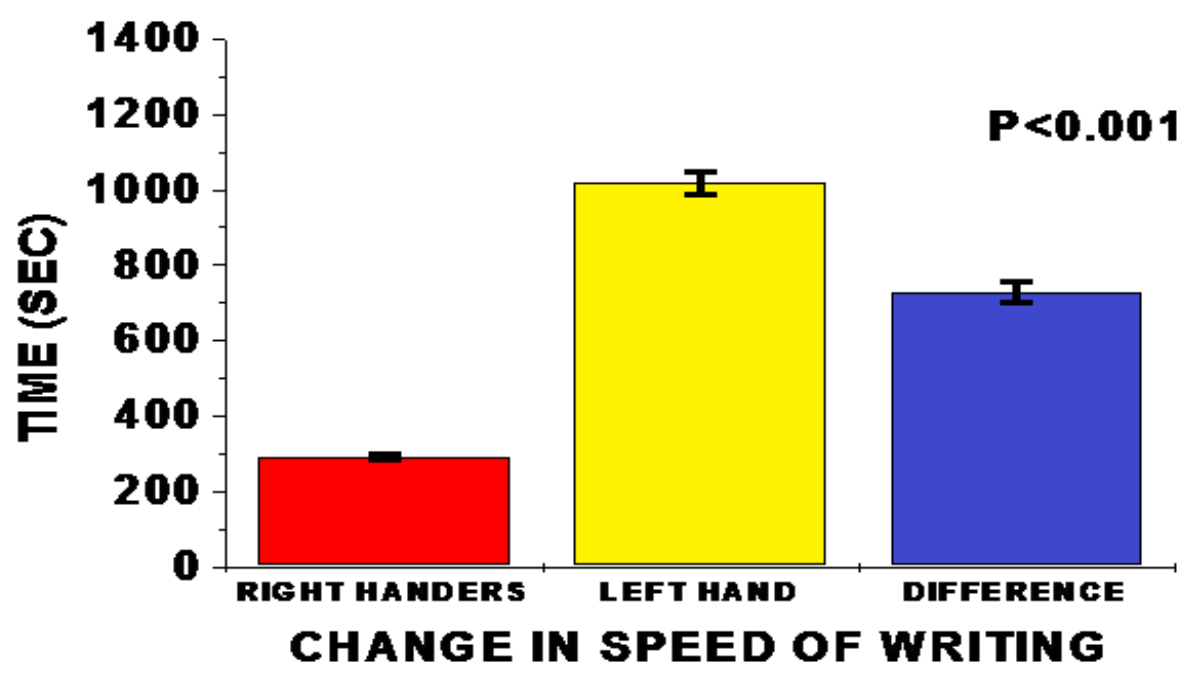

Figure 2: Difference in the speed of writing from right to left hand in seconds $(n=50)$;

\section{Means \pm SEM. $P<0.001$}

\section{DISCUSSION}

Previous studies have linked manual asymmetry or the use of preferred hand more for skilled tasks than unskilled or strength task ('Hausmann et. al 2004; Annett, 2004; Hopkins and Russell 2004). Writing is a skilled task that is not dependent on strength but rather skills and precision. Different types of manual tasks may vary according to the type and nature of the work. The degree of asymmetric hand preference was maximum for both the motor tasks in righthanders and a moderate degree of asymmetry for speed task compared to the task assessing strength in left-handers. Right hand performed better than left hand in right-handers and left hand performed better than right hand in left-handers. The comparison between normal right-handers and the left-handers in their speed of writing was statistically insignificant, though the right-handers were slightly faster than the left-handers in the procedure, In other words, the speed and dexterity in left and right handedness are the about the same. Left handers can thus compete favourably with right handers in writing task. This is in agreement with the work of (Vlachos and Bonati. 2004), who worked on handedness and writing performance and concluded that there was no significant difference in writing performance between right-handers and left-handers. As previously shown,

\section{REFERENCES}

Annett, M. (2004). Hand preference observed in large healthy samples; classification, norms and interpretations of increased non right handedness by the right shift theory. Br. J. Psychol. 95: 339-353.

Beukelaar, LJ and Kroonenberg, PM. (1983). Towards a conceptualization of hand preference. $\mathrm{Br}$ J Psycho. 74: 33-45.

Corballis, MC. (2003). From mouth to hand Gesture, speech and evolution of right handedness. Behavioral Brain Sci. 26:199-260. from this study, when left-handers used their nondominant hand (right) and when right-handers used their non-dominant hand (left), the result showed left-handers to be faster in change in hand than right-handers. The result was statistically significant; which is in agreement with the work of Dario and Anna. (1985) whose result indicates that in lefthanders, hand-foot crossed preferences are more frequent than in right-handers. The difference in time between dominant hand used by both left-handers and right-handers when compared to their change in hand to the non-dominant was statistically significant $(p<0.05)$. This indicates that left-handers are more adaptable to change in hand from dominant hand to non-dominant hand in writing when compared to right-handers. This will play a great role in Medical rehabilitation of accident victims with damage to dominant hand as left handers are likely to respond more favourably to rehabilitation than right handers.

\section{CONCLUSION}

In conclusion, there is no significant difference in the speed of writing between left-handers and righthanders in dominant hand use. However, in the change from dominant hand to non-dominant hand, left-handers were faster. Therefore, rehabilitation of left-handers with left hand injuries is much easier than right-handers with right hand injuries.

Corey, DM, Hurley, MM and Fondas, AL. (2001). Right and Left handedness defined. A multivariate approach, using hand preference and hand performance measures. Neuropsychiatric, Neuropsychology, and Behavioural Neurology. 14(3):144-52.

Dario, Salmaso and Anna, Maria Longoni. (1985). Problems in the Assessment of hand Preference. TheCortex. 21: 533-549.

Gail, D and Gillian, J. (2006). The clinical relevance of hand preference and laterality. J Physical Therapy Reviews.11 (3): 195-203 
Hausmann, M., Kirk, IJ and Corballis MC. (2004). Influence of task complexity on manual asymmetries. Cortex. 40(1):103-10.

Hopkins, WD and Russell, JL. (2004). Further evidence of right hand advantage in motor skill by Chimpanzees. Neuropsychologia.42: 990-6.

Kumar, S and Mandal, MK. (2004). Task-specific motor performance and musculo skeletal response in self classified right handers. Int J Neurosci. 113: 1487-95.

Perelle,IB, Ehrman,L. (2005). On the other hand. Behav Genet:; 35(3):343-50. Review

Reynolds, CR, Hartlage, LC, Haak, RA. (1981). The relationship between lateral preference as determined by neuropsychological performance and aptitude/achievement discrepancies. Clin. Neuropsychol. 3:1922Siebner, HR, Limmer, C, Peinemann, A, Drzezga, A, Bloem, BR. And Conrad, E. (2002). Long-term consequences of switching handedness: a positron emission tomography study on handwriting in "converted" left-handers. $J$. Neurosci. 22: 2816-2825.

Triggs, WJ, Calvanio, R, Levine, M, Heaton RK and Heilman KM. (2000). Predicting hand preferencewith performance on motor tasks. Cortex. 36:679-89.

Vlachos, F and Bonati. (2004). Handedness and writing performance. Perceptual and motor skills::Volume 98: 815-824.

Vuoksimaa, E., Koskenvuoa M., Rosea, R.J., Kaprio J., (2009). Origins of handedness: A Nationwide Study of 30161 Adults. Neuropsychologia 1294- 1301. 